\title{
PEMANFAATAN BOX PENGERING DALAM PENINGKATAN HIGIENITAS PRODUKSI KUNYIT KERING DI DESA WATES KECAMATAN SLAHUNG
}

\author{
Basuki Widodo ${ }^{1}$, Eko Yohanes Setyawan ${ }^{2}$ \\ ${ }^{1,2,3}$ Jurusan Teknik Mesin, Fakultas Teknik Industri, Institut Teknologi Nasional Malang \\ yohanes@lecturer.itn.ac.id
}

\begin{abstract}
ABSTRAK
Potensi kunyit untuk diolah menjadi berbagai macam aneka produk obat atau makanan sangat besar, karena masih banyak masyarakat yang mekomsumsi obat-obatan maupun minuman tradisional secara alami sekarang ini contohnya minuman kunir asem. Salah satu daerah penghasil kunyit adalah Kecamatan Slahung karena kondisi geografis yang cocok untuk komoditi kunyit. Dalam pengolohan kunyit mitra mengalami kesulitan dalam proses pengeringan kunyit karena dalam proses pengeringan mitra memanfaatkan energi matahari, apabila mendung atau hujan mitra mengumpulkan lagi seringkali timbul jamur karena kadar air di kunyit masih cukup tinggi. Sedangkan standar untuk kunyit kering kadar airnya maksimal $12 \%$. Sehingga tim membuat pengering kunyit dengan bahan bakar LPG yang bisa dikontrol kecepatan udara maupun temperatur yang ada didalam box pengering dan dilengkapi kaca transparan untuk melihat fisik kunyit di dalam box pengering.
\end{abstract}

Kata Kunci: kunyit, kadar air, box pengering

\begin{abstract}
The potential of turmeric to be processed into various kinds of various medicinal or food products is very large, because there are still many people who mekomsumsi medicines and traditional beverages naturally now for example the drink turmeric tamarind. One of the turmeric producing regions is Slahung Subdistrict due to geographical conditions suitable for turmeric commodity. In turmeric chewing partners have difficulty in the process of drying turmeric because in the process of drying the partners use solar energy, when cloudy or rain collecting partners often arise mushrooms because the water content in turmeric is still quite high. While the standard for dry turmeric maximum water content of $12 \%$. So the team made a turmeric dryer with LPG fuel that can be controlled air velocity and temperature in the dryer box and equipped with transparent glass to see the physical turmeric in the dryer box.
\end{abstract}

Keywords: turmeric, moisture content, box dryer

\section{PENDAHULUAN}

Daerah Ponorogo terutama pada daerah dataran tinggi banyak tumbuh tanaman kunyit yang selama ini masih belum tersentuh oleh teknologi dalam proses pengolahan kunyit, sedangkan tingkat kebutuhan masyarakat akan kunyit sangatlah tinggi, karena kunyit sangat bermanfaat sebagai bumbu masakan, bahan dasar kosmetik, bahan jamu dan yang masih banyak lagi produk turunannya yang ketersedianya tidak akan habis karena bisa ditanam kembali.

Proses pengolahan kunyit pada umumnya terdiri dari, Penyortiran dimana pemisahan kunyit dari tanah dan kotoran agar tidak tercampur dalam proses selanjutnya. Penyucian dimana ini bertujuan untuk membersihkan kunyit agar tanah yang melekat pada kunyit bisa dihilangkan. Perajangan dimana proses ini bertujuan untuk memotong kunyit agar memudahkan dalam pengeringan. dalam proses ini umumnya menggunakan tenaga manual, yaitu pemotongan dengan cara tradisional menggunakan pisau kunyit dan mengeringkan menggunakan tenaga matahari.

Proses pengolahan tersebut tentunya memakan waktu yang relatif lama khususnya pada proses pemotongan dan pengeringan. Hal ini dikarenakan beberapa faktor, yaitu minimnya tenaga yang dipekerjakan untuk memotong kunyit, dan tidak menentunya iklim cuaca yang membuat proses pengeringan tidak maksimal. Sehingga para petani lebih sering menjual kunyit dalam bentuk 
Widodo, Pemanfaatan Box Pengering Dalam Peningkatan Higienitas..

segar karena tidak memerluhkan pengolahan yang memakan banyak waktu, biaya dan tenaga. Padahal jika dilihat manfaat dari pemotongan dan pengeringan sangat banyak, yaitu memudahkan dalam penyimpanan, menjadikan kunyit tahan lebih lama, memudahkan dalam pengangkutan, menimbulkan aroma khas pada bahan serta memiliki nilai ekonomi yang lebih tinggi.

Dimana sebagian besar petani kunyit sangat kesulitan untuk mengolah bahan kunyit. Hal ini karena cuaca yang kurang mendukung untuk proses pengolahan bahan tersebut. Adapun cara pengolahan adalah dengan cara menjemurnya,hal ini menyebabkan petani kunyit di Desa Wates ini menjual hanya dengan bahan yang masih mentah dan harga dari kunyit inipun sangatlah rendah.

Sehingga dibutuhkan alat pengering kunyit, karena jika masih menggunakan cara tradisional akan ada penyusutan berat dan kurang higinis. Hal ini dikarenakan oleh proses penjemuran dengan matahari yang memakan waktu hingga 15 hari tentu membuat sebagian kunyit menjadi menjamur, dan tentunya tidak bisa dijual. Perbedaan kunyit yang dikeringkan dengan dijemur dan menggunakan pengering yaitu: Kunyit lebih bersih dengan menggunakan bok pengering, karena proses pengeringan terjadi didalam bok jadi tidak terkontaminasi oleh debu dan kotoran-kotoran lainnya dan menjadikan kunyit kering lebih cepat dari pada dijemur, hal ini mencegah kunyit yang mulai menjamur dan membusuk karena penjemuran memakan waktu 15 hari didaerah yang kelembabanya tinggi. Oleh karena itu dibuat terobosan baru, yaitu memanfaatkan box pengering untuk mengeringkan kunyit. diharapkan dapat meningkatkan penjualan kunyit secara higinis yang ada di desa wates, yang nantinya mempermudah konsumen dalam pemakaian.

\section{METODE}

Metode pendekatan yang tepat untuk meningkatkan produksi kunyit kering yang higinis yaitu dengan cara membuat box pengering tertutup. Dengan bantuan blower untuk mengeluarkan uap panas yang ada didalam bok yang mengandung air agar tidak kembali diserap oleh kunyit setelah selesai proses pengeringan.

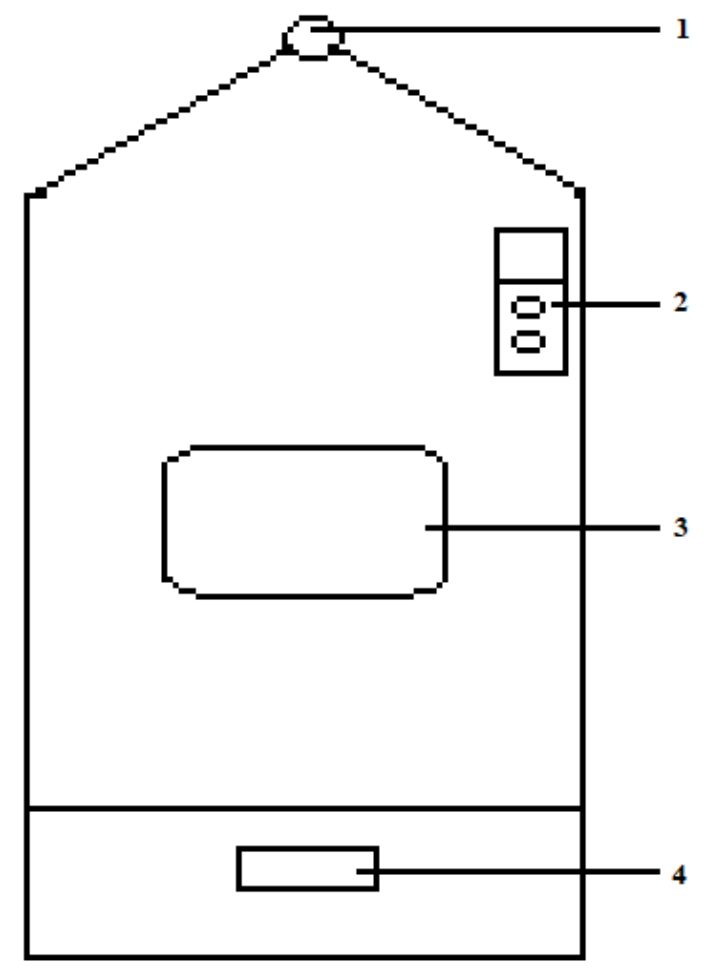

Gambar 1. Desain mesin pengering kunyit bahan bakar LPG 
Nama bagian pengering :

1. Blower digunakan untuk menyerap air pada udara didalam box pengering

2. Kontrol kecepatan blower dan temperatur, digunakan untuk mengatur kecepatan udara yang keluar dari box pengering dan menstabilkan temperatur yang ada di dalam box pengering.

3. Kaca digunakan untuk melihat fisik kunyit di dalam box pengering agar sesuai yang diinginkan.

4. Kompor sebagai sumber panas yang menggunakan bahan bakar LPG yang dilengkapi selenoid untuk mengontrol gas yang keluar dari tabung LPG.

Sistem Kerja Alat Pengering:

1. Kunyit diletakkan pada tray, dan diatur agar merata.

2. Buka katup aliran bahan bakar yang akan menyalakan api pada kompor dan atur kecepatan blower.

3. Solenoid dan katup berfungsi sebagai kontrol suhu yang diinginkan.

4. Ketika memulai, solenoid bekerja dengan mengalirkan gas yang berasal dari LPG, dan menyalakan api pada kompor yang sudah dibuka sebelumnya. Gas akan bersinggungan dengan pemantik api pada kompor, sehingga api terus menyala sampai tercapai suhu yang telah di atur pada panel kendali.

Pengering kunyit ini memiliki kontruksi yang lebih efektif dan efisien sangat dibutuhkan dengan hasil maksimal dengan kapasitas yang baik, dalam pendekatan perencanaan sebelumnya di fokuskan dalam kebutuhan kapasitas petani kunyit yang ada di Desa Wates yaitu kebutuhan dalam mengeringkan kunyit sehingga disepakati digunakan oven yang sudah dimodifikasi untuk proses pengeringan kunyit, agar tidak terkontaminasi oleh debu dan kotoran-kotoran lainnya yang menempel pada kunyit sehingga menjadikan kunyit lebih mudah busuk akibat berjamur.

\section{HASIL DAN PEMBAHASAN}

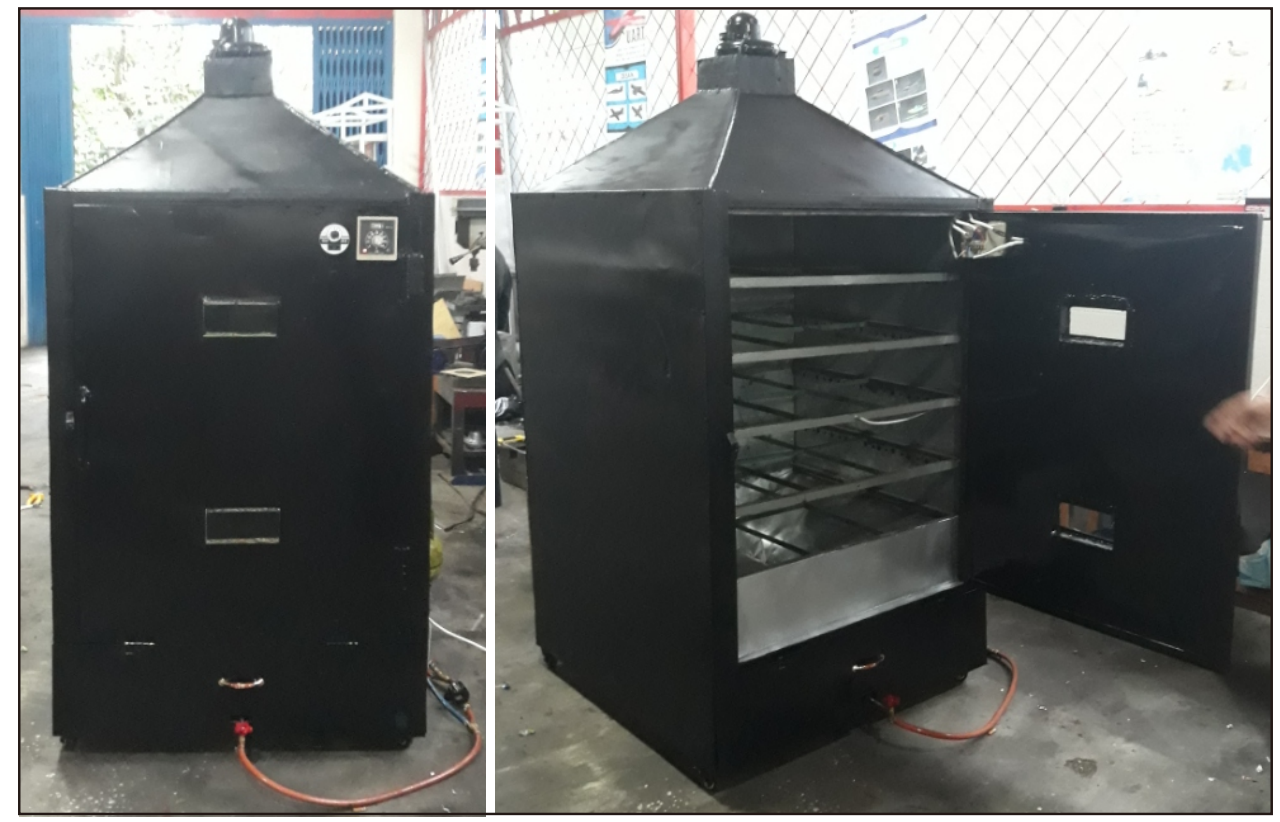

Gambar 2. Pengering kunyit

Dari hasil pengujian bersama mitra secara langsung di desa wates digunakan beberapa variasi temperatur dalam mengeringkan kunyit yaitu temperatur $45^{\circ}, 50^{\circ}, 55^{\circ}$ dan $60^{\circ}$. Dari 
beberapa variasi tersebut yang mendapatkan hasil terbaik pada temperatur $60^{\circ}$ dan standar SNI maksimal mengandung air $12 \%$. Didapatkan dengan mengukur terlebih dahulu kunyit yang akan di keringkan. Kemudian dikeringkan didalam box pengering dengan temperatur yang sudah ditentukan secara konstan, setelah itu kunyit diambil dari box pengering lalu ditimbang ulang untuk mengetahui berat akhir, kemudian dihitung berapa persen kadar air yang hilang selama proses pengeringan dengan cara (berat awal - berat akhir):berat awal x 100\%.

Kadar air sendiri merupakan sejumlah air yang berada di dalam kunyit yang dinyatakan dalam persen. Kandungan air pada kunyit berhubungan dengan jangka waktu daya tahan penyimpanan kunyit itu sendiri, semakin banyak kadar air semakin cepat rusak dan banyak jamur yang tumbuh didalam kunyit, sehingga disarankan kadar air sebesar $12 \%$ yang layak untuk disimpan. Semakin kecil kadar air semakin bagus tetapi mempengaruhi rendemen pada kunyit.

Pemanfaatan potensi kunyit untuk diolah menjadi berbagai macam aneka produk akan sangat memberikan sumbangsih yang besar bagi mitra, khususnya yang ada Kecamatan Slahung. Hal ini mengingat bahwa kunyit menjadi salah satu komoditi unggulan warga Slahung. Masyarakat setempat tidak dapat membuat berbagai produk olahan kunyit tanpa adanya penerapan teknologi. Kelayakan teknis pengolahan kunyit sangat memungkinkan bila ditinjau dari kondisi geografis dan produktifitas masyarakat.

Dengan adanya mitra industri rumahan tersebut, diharapkan akan menjadi salah satu sumber pendapatan daerah Slahung. Meningkatkan nilai tambah kunyit mulai penanaman, panen dan pascapanen sampai menjadi produk bernilai akan memberikan umpan balik bagi masyarakat setempat atau produsen. Secara keseluruhan pengabdian di desa Wates sudah maksimal, mitra sudah bisa mengoperasikan pengering kunyit serta memahami kontrol yang ada, yaitu kecepatan udara dan pengatur temperatur. Dari sini, mitra bisa meningkatkan hasil produksinya karena sudah ada pengering. Mitra tidak perlu khawatir lagi akan kerusakan pada kunyit karena berjamur, pengering mampu menghasilkan kunyit dengan kadar air maksimal 12\% dan warna yang kuning-jingga tidak gosong sehingga bisa dijadikan produk olahan sesuai kebutuhan.

\section{DAMPAKDAN MANFAAT}

Dampak maupun manfaat yang didapatkan oleh masyarakat di Desa Wates, Kecamatan Slahung, yaitu dalam proses pengering kunyit tidak perlu khawatir, apabila kunyit yang dikeringkan menggunakan sinar matahari tidak kering karena datangnya hujan maupun mendung bisa memanfatkan alat pengering. Karena kunyit yang dikeringkan dalam beberapa hari yang belum mencapai kadar air 12\% akan menimbulkan jamur pada kunyit tersebut, selain nilai jual yang turun juga akan menimbulkan racun pada kunyit. Dengan menggunakan box pengering ini selain lebih higienis karena proses pengeringan yang dilakukan di dalam box, kecepatan udara dan temperatur bisa di kontrol sesuai keinginan agar mendapatkan hasil yang maksimal.

\section{KESIMPULAN}

Kunyit merupakan tanaman obat yang banyak tumbuh di daerah dingin salah satunya ada di desa wates kecamatan slaung. Karena kunyit merupakan tanaman obat harus higienis dalam proses pengolahannya, yaitu dengan memanfaatkan box pengering dengan bahan bakar LPG yang sudah dilengkapi kontrol kecepatan udara dan kontrol temperatur untuk mendapatkan hasil yang maksimal, serta menghasilkan kadar air maksimal sebesar 12\% agar dapat disimpan lebih lama untuk mendapatkan harga yang sepadan yang mampu bersaing dengan industri kunyit kering yang lain. 
Jurnal Aplikasi dan Inovasi Ipteks, Vol. 1 / No. 1 / April 2018; 1-10

\section{UCAPAN TERIMA KASIH}

Ucapan terima kasih disampaikan kepada Lembaga Penelitian dan Pengabdian ITN Malang yang telah mendukung pendanaan untuk kelancaran program penelitian dan pengabdian yang telah dilakukan.

\section{DAFTAR PUSTAKA}

Ambarita Himsar, Setyawan Eko Yohanes dan Nasution Halim. 2017. Optimasi Mesin Sabut Kelapa Dan Gagang Kayu di Kabupaten Serdang Bedagai Sumatra Utara, Seminar Nasional dan Gelar Produk 2017, Universitas Muhamadiyah Malang, Indonesia 1202-1212

Djiwo Soeparno Dan Eko Yohanes. 2016. Mesin Teknologi Tepat Gunasabut Kelapa di UKM Sumber Rejeki Kabupaten Kediri. Seminar Nasional dan Gelar Produk 2016, Universitas Muhamadiyah Malang, Indonesia 576-582

Dessler, Gary. 2006. Manajemen Sumber Daya Manusia, Edisi Kesepuluh. Jakarta.

R.Paramitasari, 2011, Panduan Praktis, Lengkap, dan Menguntungkan Budi Daya Rimpang Jahe, Kunyi, Kencur, Temulawak. Cahaya Atma, Yogyakarta

Karyasari, 2011. Kunir Putih. http://www.familyherba.web.id/Kunyit-putih-kunir-putih.html akses tanggal 13 April 2017, Malang.

Kumalaningsih, 2006. Antioksidan Alami Penangkal Radikal Bebas. Trubus Agrisarana. Surabaya.

Kriswanto, 2011. Asal Usul Kunyit Putih. http://www.madukunyitputih.com/Asal-Usulkunyitputih. akses tanggal 13 April 2017, Malang.

Mahmud, Hermana, Nils Ari Zulfianto., 2009. Tabel Komposisi Pangan Indonesia.

Gramedia, Jakarta.

Muchtadi, Sugiyono, Fitriyono, 2010. Ilmu Pengetahuan Bahan Pagan. Alfabeta, Bandung.

Raina, 2011. Eksiklopedi Tanaman Obat untuk Kesehatan. www.ensiklopesdia/tanaman /obat/indonesia.co.id 13 April 2017, Malang.

Setyawan Eko Yohanes, Djiwo Soeparno and Sugiarto Totok. 2017. Simulation Model of Fluid Flow and Temperature Distribution in Porous Media Using Cylinder Convergent and Divergent Nozzle. Internasional Journal of Technology And Sciences. 